\title{
A Economia Solidária ante a globalização: o caso das moedas sociais
}

Nicole Julie Fobe

\section{Resumo:}

Com o advento da globalização, ocorre o aumento das desigualdades sociais e econômicas, culminando no aparecimento de conglomerados poderosos, como as grandes empresas transnacionais, contrapostos a comunidades empobrecidas e carentes. Este trabalho tem por objetivo analisar um caso específico de reação ao fenômeno da globalização: as moedas sociais - aliadas ao fortalecimento dos ideais da Economia Solidária - e relacionar esta iniciativa à inserção do Brasil no cenário econômico internacional.

Palavras-chave: moedas sociais - desenvolvimento - globalização - Economia Solidária 
[...] nada é mais difícil na sua preparação, mais duvidoso no êxito e mais perigoso nos seus efeitos que estar junto com pessoas que querem promover inovações. Nicolau Maquiavel

\section{Globalização e economia}

[...] dois movimentos diametralmente opostos: o da globalização ou integração econômica [...] e o da fragmentação sociocultural, uma vez que a globalização é um processo de decisões privadas e públicas tomadas na forma de sucessivos e inacabados desafios e ajustes, gerando intensas transformações cujas origens e consequências são extremamente complexas, por causa de suas múltiplas dimensões não econômicas (FARIA, 20IO, p. I34).

Globalização é o fenômeno inerente ao modo de produção capitalista, que tem por característica a fusão entre sistemas econômicos e financeiros dos diversos Estados que compõem o mundo contemporâneo. ${ }^{I}$ A partir da segunda metade do século XX, o desenvolvimento dos sistemas de produção, dos meios de transporte e principalmente a evolução da tecnologia dos meios de comunicação fez com que as fronteiras entre os países ficassem cada vez mais tênues, o que culminou em relações de interdependência ${ }^{2}$ (entre países desenvolvidos e subdesenvolvidos) e intradependência (entre os próprios países desenvolvidos ou entre os países subdesenvolvidos). A especialização da produção fez com que os Estados que realizaram suas revoluções industriais primeiro detivessem tecnologia e um parque industrial suficiente para desenvolver produtos com alto valor agregado, produtos estes que seriam exportados aos Estados que não haviam implementado ou implementaram tardiamente uma política de industrialização nacional. Estes, por sua vez, especializar-se-iam na exportação dos produtos primários, matérias-primas, de menor valor agregado e bastante sensíveis a variações de preço no mercado internacional. Essa polarização da produção levou ao surgimento das empresas multinacionais, que

I "Globalization of the world economy denotes a process based on the formation of a single market for goods, services and factors of production, including capital, labour, technology and natural resources, covering all countries and economic regions. In the process, national and international markets are combined into a single complex whole. From a theoretical point of view, globalization means an unlimited access to these markets for all interested businesses regardless of country of origin and economic region" (BOŻYK, 2006, p. I).

2 Gf. HENDERSON, I999, p. 5I. 
terminaram por acentuar as disparidades entre o mundo industrializado e o mundo semi ou não industrializado.

As empresas multinacionais (ou transnacionais), por meio da abertura do seu capital e/ou subsídios governamentais, transferiram suas fábricas para países do mundo subdesenvolvido ${ }^{3}$ com o objetivo de (i) contratar mão de obra barata, ainda que desqualificada; (ii) estabelecer complexos fabris em locais com leis ambientais brandas ou contornáveis; (iii) procurar incentivos fiscais dos governos locais; (iv) explorar a proximidade do fornecimento de matéria-prima. As gigantes multinacionais, organizadas e com poder de barganha, terminaram por impor as suas vontades e modus operandi aos governos dos Estados subdesenvolvidos, ${ }^{4}$ que viam na atuação delas a criação de empregos e riqueza, o que - teoricamente - aqueceria também a economia local. O resultado, como não podia deixar de ser, foi desastroso para as nações exploradas. ${ }^{5}$

Tamanha exploração da mão de obra, dos recursos naturais e dos incentivos governamentais alterou o sistema social, econômico, cultural e político. No plano social, tem-se a pressão pela redução dos direitos trabalhistas, pela diminuição dos salários, pelo aumento das horas trabalhadas, enfim, a pressão para que se produza o máximo possível a partir do mínimo necessário, ainda que - em um primeiro momento - a qualidade dos produtos possa deixar a desejar. A migração inter-regional também é um reflexo desse processo. A instalação de parques industriais atrai mão de obra barata e desqualificada, que tende a migrar para as grandes cidades ou para polos empresariais. A economia torna-se cada vez mais dependente dos recursos estrangeiros, já que a indústria nacional não tem força para competir com o poder comercial, econômico, tecnológico e político das empresas estrangeiras. ${ }^{6}$ Além disso, o mercado consumidor, alimentado por baixos salários,

3 Cabe salientar que os países explorados receberam apenas as fábricas e filiais das empresas transnacionais: os seus núcleos de decisão permaneceram nos países de origem, o que acentua a hipótese de que essas empresas tinham por objetivo justamente a exploração de condições mais favoráveis, e não o investimento efetivo no país em que este se fazia necessário (CHANG, 2004, p. 252).

4 Chang (2004, p. 266) aponta para o fato de que há alguns poucos casos em que os países subdesenvolvidos têm certo poder de barganha, como os exemplos da Coreia, Singapura e Malásia, que conseguiram fazer com que as próprias transnacionais competissem entre si (p. 262) para adentrar nos seus mercados internos. No entanto, como ressaltado pelo autor, estes são casos excepcionais. A regra é, como foi dito, a imposição.

5 Para um panorama geral a respeito do efeito das empresas transnacionais nos países subdesenvolvidos, ver CHANG, 2004, p. 248 e ss.

6 Gf. BOŻYK, 2006, p. 5. 
não se configura como demanda suficiente para despertar interesse no empreendedorismo local. No âmbito cultural, assiste-se a uma desvalorização da cultura nacional, cada vez mais influenciada - senão atropelada - pelas influências estrangeiras. ${ }^{7} \mathrm{O}$ internacional é cobiçado, torna-se sinônimo de status. O nacional simboliza justamente o contrário. Finalmente, no campo político, há uma aproximação entre o corpo gerencial das empresas estrangeiras e os governos dos Estados subdesenvolvidos, que são utilizados como instrumentos para garantir a exploração dos recursos e a produção eficiente. Percebe-se, assim, um distanciamento entre as classes governadas e as classes governantes, que deixam de atender aos interesses do povo, atentando aos "benefícios" trazidos pela indústria estrangeira. Ademais, cabe salientar que a infraestrutura até então incipiente no país explorado é fomentada no sentido de tornar mais fácil o acesso das indústrias aos insumos e o escoamento da produção aos portos e aeroportos. Tem-se, portanto, uma desvalorização do espaço e o surgimento de complexos sem o menor planejamento urbanístico: cidades-satélite ao redor de complexos fabris, estradas de ferro ligando exclusivamente polos industriais a portos, casas, bairros e ruas em completa dissonância com o meio ambiente e sem atenção adequada ao espaço disponível e às condições do território.

Esse foi o processo vivido pelo continente africano, grande parte do continente asiático e, principalmente, pelas jovens democracias da América Latina. Não é por outro motivo que, nas décadas seguintes, assistir-se-á a uma verdadeira militarização dos governos (ou, em alguns casos, à ascensão de governos igualmente autoritários), que até então eram cúmplices do capital estrangeiro. Os governos militares ou autoritários, com base nos efeitos cruéis trazidos pelas empresas multinacionais, manterão um discurso nacionalista, focando (i) no incentivo à indústria nacional, por meio do modelo de substituição de importações; (ii) na valorização da cultura do país; (iii) no fomento ao desenvolvimento tecnológico e científico; e (iv) na promessa de manter um governo incólume, no interesse dos governados. O Brasil viveu esse momento, viveu esse discurso. O governo militar e, antes dele, o go-

7 "Se é verdade que as transnacionais tiveram de realizar um esforço de adaptação a mercados estreitos e ainda em formação, não o é menos que elas em seu natural empenho em maximizar a rentabilidade em que se instalavam se adaptassem o mais possível aos padrões de consumo que prevaleciam nos países centrais. Vimos que nestes as empresas transnacionais operaram no sentido de homogeneizar os mercados nacionais, pois isso lhes permitia maximizar as vantagens derivadas das economias de escala e do controle da inovação [...]" (FURTADO, I987, p. 207). 
verno de Getúlio Vargas, ${ }^{8}$ tiveram por estratégia justamente a adoção de todas as medidas elencadas acima, como forma de promover o desenvolvimento econômico - do país.

O fim do governo militar, no entanto, deixou diversas sequelas à recém- nascida democracia brasileira. O endividamento externo (FURTADO, I987, p. 2IO), ${ }^{9}$ a falta de maturidade política e a disparidade social terminaram por agravar os problemas que já assolavam o Brasil. Os planos econômicos que se seguiram, aliados à inflação galopante, culminaram no desemprego em massa e na desvalorização dos produtos nacionais. Como consequência direta desse processo, nas décadas de I980 e I990, o país apresentaria um índice de crescimento bastante modesto, pondo fim ao "milagre econômico" que até então se sustentara sobre frágeis bases sociais, políticas e econômicas.

\section{O conceito de Economia Solidária}

O fato de o desenvolvimento, em tempos de reestruturação, ter acentuado a liberdade do mercado em detrimento dos controles dos Estados nacionais sobre a dinâmica do capital não anula o outro fato, de que a revolução microeletrônica e telemática contribuiu para que o capital produtivo (não o financeiro) se descentralizasse, abrindo espaço para um desenvolvimento misto de pequenas e médias empresas e de complexos cooperativos, guiado pelos valores da solidariedade (SINGER, 2004, p. 2I).

"Economia Solidária é um jeito diferente de produzir, vender, comprar e trocar o que é preciso para viver. Sem explorar os outros, sem querer levar vantagem, sem destruir o ambiente. Cooperando, fortalecendo o grupo, cada um pensando no bem de todos e no próprio bem." Io

O movimento da Economia Solidária surgiu com a própria Revolução Industrial, com a criação, pelos trabalhadores, de corporações e cooperativas para a proteção de suas atividades e, indiretamente, de seus interesses. No

8 Cf., para uma análise detida dos impactos econômicos gerados pelo modelo de substituição de importações, implantado por Getúlio Vargas, FURTADO, I987, p. I83.

9 "O endividamento externo desordenado outra coisa não é senão uma consequência dessa perda de comando do sistema econômico, além de ser um fator autônomo de realimentação do referido processo de internacionalização" (FURTADO, I987, p. 2I4).

Io Conceito de Economia Solidária desenvolvido pelo Ministério do Trabalho e Emprego. Disponível em: 〈http://www.mte.gov.br/ecosolidaria/ecosolidaria_oque.asp〉. Acesso em: o9 out. 2010. 
Brasil, o movimento foi institucionalizado em 2003, com a criação da Secretaria Nacional da Economia Solidária (SENAES), ligada ao Ministério do Trabalho e do Emprego.

Em I7 de novembro de 20I0, foi criado no Brasil o primeiro Sistema de Comércio Justo e Solidário do mundo, reconhecido e fomentado pelo Estado, e instituído pelo Decreto n⿳ 7.358. Dentre as suas disposições, salientamos os artigos $2^{\circ}$ e $3^{\circ}$, que trazem um bom panorama do significado e implicações da Economia Solidária.

Art. 2 Para os efeitos deste Decreto, entende-se por:

I - comércio justo e solidário: prática comercial diferenciada pautada nos valores de justiça social e solidariedade realizada pelos empreendimentos econômicos solidários;

$[\ldots]$

Art. 3ㅇ O SCJS tem por finalidade fortalecer e promover o comércio justo e solidário no Brasil, o que compreende alcançar os seguintes objetivos:

I - fortalecer identidade nacional de comércio justo e solidário, por meio da difusão do seu conceito, de seus princípios e critérios de reconhecimento de práticas de comércio justo e solidário e de seu fomento;

II - favorecer a prática do preço justo para quem produz, comercializa e consome; III - divulgar os produtos, processos, serviços, bem como as experiências e organizações que respeitam as normas do SCJS;

$[\ldots]$

VII - apoiar processos de educação para o consumo, com vistas à adoção de hábitos sustentáveis e à organização dos consumidores para a compra dos produtos e serviços do comércio justo e solidário.

Cumpre, para o presente trabalho, explorar dois dos princípios da Economia Solidária: (i) a cooperação, entendida como a busca de interesses e objetivos comuns para um determinado grupo de pessoas; e (ii) a autogestão, ou seja, o desenvolvimento, pelo próprio grupo, das atividades essenciais à sua manutenção e evolução. O apoio externo é possível e desejável, desde que não inviabilize a gestão dos próprios sujeitos envolvidos.

O movimento também tem uma posição contrária à globalização. Não no sentido combativo, e sim quanto ao reconhecimento das implicações do fenômeno, elencadas acima. Sendo assim, a Economia Solidária valoriza a cultura nacional, viabiliza um mínimo de inclusão econômica de grupos à margem da economia formal, e leva ao debate político diversas questões relativas à expansão do movimento. 
As moedas sociais, que serão examinadas no próximo tópico, têm por característica exatamente a valorização do local contraposto ao global. ${ }^{\mathrm{II}} \mathrm{A}$ maioria das moedas leva o nome de algum produto ou algum traço regional. ${ }^{12}$ Além disso, a principal proposta do instrumento é a inclusão econômica de pessoas e comunidades que acabaram marginalizadas pela globalização, quer por não serem mão de obra qualificada o suficiente, quer por não se constituírem enquanto mercado consumidor relevante. O fenômeno foi aqui classificado como um desdobramento da Economia Solidária justamente por se enquadrar nos seus objetivos e princípios, bem como estar diretamente a ela relacionado, por virtude do seu caráter comunitário e de desenvolvimento local contraposto ao regime econômico e financeiro nacional.

\section{Uma experiência: as moedas sociais}

Portanto, quanto mais lentas (ou postergadas) são a estabilização econômica e a reforma social, [...] mais as desigualdades se agravam e mais se debilita o acordo moral básico do qual dependem a manutenção da ordem democrática e o funcionamento da economia. E quanto maior é a velocidade desse processo, menor é a efetividade dos direitos fundamentais restabelecidos pela abertura política, uma vez que a miséria, as decepções e a falta de perspectivas minam a estabilidade institucional, esgarçam os laços de solidariedade e abrem caminho para o "hobbesianismo social" (FARIA, 20IO, p. I29-I30).

Tudo começou em uma favela de 30.000 habitantes, no interior do Ceará, quando alguns líderes de uma comunidade extremamente carente deram início ao primeiro caso de sucesso dos bancos comunitários.

O que se pretende abordar neste trabalho é um outro produto desta parceria. As moedas sociais, instrumento poderoso e certamente necessário ao sucesso do empreendimento, chamam a atenção pela potencialidade e, ao

II No Conjunto Palmeiras, por exemplo, quando da implantação do Banco Palmas, os coordenadores do projeto incentivaram o consumo de produtos locais em detrimento dos "importados". Para viabilizar a criação de marcas locais, o Banco abriu uma linha de crédito específica para empreendedores, e hoje há cooperativas para a produção de produtos de limpeza "Palmas", roupas "Palmas" e alguns outros produtos de consumo.

12 Como exemplo, temos o Maranhão, o Castanha, o Pará e o Palma. 
A Economia Solidária ante a globalização: o caso das moedas sociais

mesmo tempo, pela desregulamentação absoluta. Não há, no Brasil, marco regulatório algum em se tratando de moedas complementares. ${ }^{13}$

R\$ I.200.000,00 (um milhão e duzentos mil reais). Era essa a quantia gasta mensalmente por todos os moradores do Conjunto Palmeira. Diante dessa quantia, os líderes da Associação de Moradores perguntaram-se como o bairro podia ser tão pobre, e chegaram à conclusão de que o problema não estava na arrecadação, e sim na circulação do dinheiro: os moradores gastavam fora do Conjunto, ou seja, ganhava-se o dinheiro na comunidade, mas não se gastava nela: o desenvolvimento era tolhido pelos próprios habitantes. Surge então uma proposta visando à permanência do meio circulante no próprio bairro. Como já havia sido experimentado com sucesso em outros lugares (como o WIR, na Suíça e o LETS, no Canadá e Estados Unidos), ${ }^{14}$ deu-se início à implantação de um mecanismo alternativo à moeda oficial: o Palma.

I3 Muito embora a Constituição Federal de I988 disponha que é competência exclusiva da União a emissão de moeda (art. I64), argumenta-se que as moedas sociais possuem natureza diversa da moeda nacional de curso forçado, além de não terem por objetivo - teoricamente - a substituição ou restrição ao uso do Real.

Atualmente, o Banco Central e a SENAES (Secretaria Nacional de Economia Solidária) estudam uma possível parceria para regular a moeda social. Tramita também no Congresso Nacional o Projeto de Lei Complementar no 93/2007, apresentado pela deputada Luiza Erundina. O PL estabelece a regulamentação dos bancos comunitários e das moedas sociais. Dispõe o artigo IO:

"Art. IOOㅗ B Bancos Populares de Desenvolvimento Solidário estão autorizados a prestar os seguintes serviços financeiros, nas condições e limites fixados pelo Conselho Nacional de Finanças Populares e Solidárias, e mediante expressa autorização do mesmo: X - Operar moedas sociais de circulação adstrita à sua área de atuação”

I4 O WIR, Wirtschaftsring-Genossenschaft, também conhecido como Círculo Econômico Suíço, foi criado em I934 e é, até hoje, uma das experiências mais bem-sucedidas em se tratando de moedas paralelas. Considerado um dos responsáveis por retirar a Suíça da recessão europeia, o sistema foi assimilado pelo Estado e hoje convive lado a lado com o Franco Suíço. Estima-se que, atualmente, a comunidade que utiliza o WIR ultrapassa 62.000 pessoas e o volume de trocas supera I bilhão de euros. Já o LETS (Local Exchange Trading System) que funciona em diversos países, dentre eles Austrália, Canadá, Estados Unidos e Coreia do Sul, não possui uma moeda física alternativa. O sistema funciona na base prestação de serviço/crédito correspondente. Os indivíduos interessados cadastram-se no sistema e ganham créditos a partir de serviços realizados, como cortar a grama do vizinho, consertar um eletrodoméstico, cuidar de crianças, fornecer assistência técnica ou jurídica, etc. Esses créditos são debitados em contas nos supermercados locais, e podem ser utilizados na compra de produtos ou na contratação de serviços não fornecidos pela rede LETS. O crédito obtido no sistema tem o seu valor equiparado à moeda oficial, e todas as transações são realizadas eletronicamente. 
Os líderes comunitários reuniram-se com os comerciantes da região, com $\mathrm{ONGs}_{\mathrm{s}}{ }^{\mathrm{I}}{ }^{\mathrm{com}}$ parceiros estrangeiro ${ }^{16}{ }^{\mathrm{e}}$ com instituições financeiras $^{\mathrm{I7}}$ e iniciaram a emissão da primeira moeda social brasileira. A integração entre todos os grupos econômicos da região foi vital para o sucesso do empreendimento. Como se verá adiante, a relação de confiança é fundamental à concepção de moeda social - e ao conceito de moeda como um todo.

Para manter a moeda circulando apenas no bairro, e coibir a "fuga" de capital, a implantação do sistema baseou-se em duas frentes: os comerciantes e os consumidores. Comecemos a análise pelos comerciantes.

Os comerciantes que desejavam expandir seus negócios podiam fazer um empréstimo do Banco Palmas em reais, mas só podiam saldar sua dívida em palmas. Se, posteriormente, o comerciante precisasse efetuar uma compra de um fornecedor externo à comunidade, ele poderia trocar os palmas que tivesse por reais. Isso forçaria o comércio local a aceitar a moeda local em vez do Real. Além disso, convencionou-se, para o bem da comunidade, que os empreendedores deveriam dar um desconto de 5 a IO\% aos clientes que realizassem seus pagamentos em moeda social. Essa estratégia tinha por objetivo não apenas popularizar o uso dessa moeda, mas também aumentar a confiabilidade da população e, como benefício ao comerciante, haveria ainda a fidelização do consumidor. Em 2009, 240 empreendimentos, entre produção, comércio e serviços, aceitavam a moeda local.

Já os consumidores poderiam adquirir palmas de duas maneiras: trocando a moeda nacional pela moeda local, ou através de um empréstimo sem juros. Incentivados pelos descontos no comércio local e sensibilizados pelo ideal de ajuda à comunidade, lentamente o Real passou a ser retirado de circulação. Há moradores, inclusive, que alegam não possuir mais nota oficial alguma.

I5 As ONGs que colaboraram com a implantação do Banco Palmas foram (i) a Cearah Periferia, que emprestou os primeiros $\mathrm{R} \$ 2.000,00$ necessários ao funcionamento do banco e (ii) a Sitawi, que também contribuiu com recursos.

I6 O InStroDI (Instituto Strohalm de Desenvolvimento Integral) é uma Organização da Sociedade Givil de Interesse Público (OSCIP) que existe no Brasil desde 2002. O Instituto é parte da Fundação holandesa STRO (Social Trade Organisation), que desde I970 fornece know-how, treinamento e recursos a iniciativas locais de desenvolvimento.

I7 O Banco do Brasil, por meio do Banco Popular do Brasil (BPB), disponibiliza uma carteira de crédito para o Instituto Palmas no valor de I, 5 milhão de reais, e atua como correspondente bancário em outras comunidades, aceitando o palmas para o pagamento de contas e demais ações bancárias. Além disso, em 2009 o Banco Central assinou um termo de parceria com o Ministério do Trabalho (SENAES) para criar um marco regulatório que tenha por objeto os bancos comunitários e as moedas sociais. 


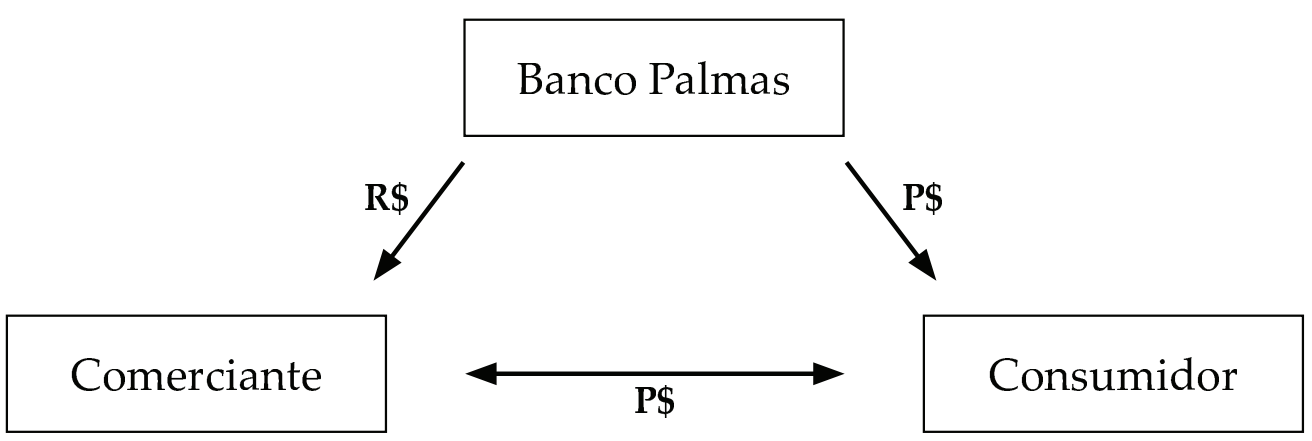

O "dinheiro" novo, por ser aceito apenas localmente, não pode ser gasto em outras cidades. Isso faz com que não ocorra a "fuga" de capital, que impedia o desenvolvimento e o enriquecimento do bairro. Dispondo de recursos, a Associação dos Moradores conseguiu transformar o que antes era apenas uma favela, sem saneamento básico e com poucas iniciativas, em um bairro reformado e empreendedor, cujo conceito de banco comunitário é hoje exportado para diversas cidades do Brasil.

O modelo do Banco Palmas tem ainda outras peculiaridades. Ele atua em um setor no qual o sistema bancário nacional não consegue penetrar, devido ao excesso de burocracia necessária e à exigência de que as instituições financeiras sigam os parâmetros do Sistema Financeiro Nacional. Os moradores, por exemplo, não conseguem ter acesso a empréstimos da rede oficial devido aos juros elevados e à exigência de diversos comprovantes e documentos que a maioria não sabe como conseguir. ${ }^{18}$ Semelhantemente ao ganhador do Nobel de economia, Muhammad Yunus, criador do Grameen Bank, ${ }^{19}$ a iniciativa

I8 Segundo dados levantados pelo IPEA, 60\% da população brasileira nunca entrou em uma agência bancária. No Nordeste, o índice de adultos sem uma conta em banco ultrapassa os 50\%. In: "Sem banco' guardam R\$ 650 bilhões embaixo do colchão no Brasil”. O Estado de S. Paulo, São Paulo, IO maio 20I3. Caderno Economia \& Negócios. Disponível em: <http://economia.estadao.com.br/noticias/ economia-geral, sem-banco-guardam-r-650-bilhoes-embaixo-do-colchao-no-brasil, I53374, o.htm > . Acesso em: II maio 20I3.

I9 O Grameen Bank (Bangladesh) foi a primeira iniciativa do mundo a fornecer microcrédito, focando principalmente na concessão de crédito a mulheres pobres. Atualmente conta com 2.I85 agências, já emprestou dinheiro para 6,6I milhões de pessoas (97\% das quais são mulheres) e sua taxa de inadimplência é de I, I5\% (informações retiradas de: 〈http://www.grameen-info.org/〉. Acesso em: 20 maio 20IO).

Cabe salientar que há uma iniciativa semelhante no Brasil, do Banco do Nordeste, chamada GrediAmigo. Considerado por Paul Singer a "maior entidade de microcrédito da América Latina", o programa possui cerca de 400 mil clientes ativos (SINGER, Paul. "BC discute regulação de moedas sociais". Revista 
brasileira visava à concessão de microcrédito àqueles excluídos do sistema de crédito bancário oficial. Porém, Bernard Lietaer, entusiasta das moedas complementares ${ }^{20}$ e um dos responsáveis pelo implemento do Euro, em entrevista à Folha de S.Paulo ${ }^{2 \mathrm{I}}$ afirmou que o Banco Palmas ultrapassa em complexidade o Grameen Bank, assemelhando-se mais ao WIR, rede que transaciona também em moeda nacional. ${ }^{22}$

$\mathrm{O}$ avanço em relação ao empreendimento de Bangladesh consiste em manter o dinheiro circulando apenas localmente. Com um espaço delimitado, além de conceder empréstimos a pessoas carentes e incentivar novas iniciativas comerciais, consegue-se multiplicar o desenvolvimento dentro da comunidade, sem eventuais "perdas" para comércios ou fornecedores de outras localidades. Além disso, a criação de um instrumento monetário traz uma integração ainda maior entre os moradores da comunidade, o que, de acordo com João Joaquim de Melo Segundo, um dos fundadores do Banco Palmas, é imprescindível ao sucesso de um banco comunitário. Ou seja, para além do fornecimento de empréstimos sem juros a uma comunidade carente, o banco cearense esmerou-se em promover a solidarização entre os moradores e a retenção do dinheiro no local, o que teve por consequência o desenvolvimento da comunidade como um todo, e não apenas de iniciativas individuais. Hoje, o volume de compras na região gira em torno de $\mathrm{R} \$ 6$ milhões: ${ }^{23}$ quatro vezes superior ao período anterior à moeda social.

\section{Conclusão}

O fenômeno das moedas sociais atua, portanto, na contramão do fenômeno da globalização. Ele possibilita, por meio do "fechamento" da comunidade em relação ao Brasil e ao mundo, a criação de uma poupança interna à comunidade que financia o seu posterior desenvolvimento. O modelo teve tamanho

\footnotetext{
do Brasil Online, 20 out. 2009. Disponível em: < http://www.facesdobrasil.org.br/component/content/ article/6-comercio-justo--economia-solidaria/492-bc-discute-regulacao-de-moedas-sociais-revela-paul-singer-revista-do-brasil.html >).

20 A grande virtude das moedas sociais está, segundo ele, no fato de que elas possibilitam trocas que, de outra forma, não ocorreriam. Elas conectam recursos, impulsionam a economia local e promovem uma solução sistêmica e endógena, bem como possibilitam a criação de uma poupança interna. 2 I Folha de S.Paulo, São Paulo, 02 fev. 2009.

22 Embora realize transações em reais (concedendo empréstimos a comerciantes, por exemplo), o Banco Palmas só coloca em circulação a sua própria moeda.

23 ValorOnline, São Paulo, 04 fev. 2010.
} 
sucesso que foi implantado em outros 40 municípios no Brasil, totalizando hoje 5I Bancos Comunitários e, como consequência, 5I moedas diferentes em circulação. ${ }^{24}$

O fato de uma moeda social ser, no sentido jurídico do termo, "moeda", traz consequências negativas ao conceito de Estado, vez que a soberania - componente da conceituação - implica também a emissão, em caráter de exclusividade, de moeda própria. Ou seja, em última análise, estar-se-ia colocando em cheque o próprio conceito de soberania.

Uma argumentação possível vai no sentido de que as moedas sociais comportam-se como títulos de crédito, não se constituindo como moeda no sentido jurídico. Ascarelli, em sua Teoria geral, ao tratar da diferenciação entre título de crédito e dinheiro, apresenta a seguinte afirmação:

É nesse caso que surge o problema da concorrência econômica ao papel-moeda. Isso, aliás, é natural, atendendo-se a que o papel-moeda, nas suas origens, não passava de um título ao portador, título abstrato, para o pagamento à vista de certa quantia de dinheiro; dinheiro, então, era o ouro.

A qualidade de título de crédito não é incompatível com a de moeda. Com efeito, para decidir o que constitui moeda (conceito mais amplo que o de "moeda legal") é necessário considerar o que de fato é correntemente dado e aceito como instrumento de troca; daí a possibilidade de determinado título de crédito acabar sendo considerado como "moeda" (ASCARELLI, I969, p. 307).

É possível, portanto, que as moedas sociais sejam consideradas moeda no sentido econômico e moeda no sentido sociológico, já que, para tanto, basta que sejam reconhecidas enquanto unidade de valor pela comunidade que as utiliza. Como forma de evitar o potencial conflito que existe quanto ao conceito jurídico de moeda, no entanto, é possível afirmar que o instrumento constitui título de crédito, uma vez que o próprio dinheiro, antes do seu reconhecimento oficial pelo Estado, também pode ser caracterizado como tal. O Brasil convive hoje, assim, com uma realidade na qual existem diversos meios circulantes, paralelos ao real - moeda oficial - promovendo a circulação da economia. Pode-se adotar uma atitude defensiva, proibindo a emissão de instrumentos semelhantes, ou controlando a sua emissão, ou mesmo regulando e restringindo a sua circulação. Mas é preciso levar em conta o impacto social positivo que as moedas sociais têm trazido, como o incentivo à circulação da riqueza, 
o crescimento exponencial experienciado pela população, o investimento em setores deficitários da economia da região, bem como a criação de mecanismos internos de resolução de disputas e promoção do desenvolvimento humano e econômico. Além disso, nota-se também o alto grau de coesão interna assumido pelas comunidades que adotam moedas sociais.

A título de conclusão, muito embora o Brasil estivesse inserido na lógica de dependência que foi descrita acima como típica dos países subdesenvolvidos, o final do século XX e o século XXI têm mostrado que a presença estrangeira foi essencial para o desenvolvimento econômico que temos experimentado hoje. Esse desenvolvimento, no entanto, tem alcançado aqueles que estão inseridos na lógica de mercado. As comunidades como o Conjunto Palmeira, explorado no presente trabalho, não têm, em um primeiro momento, condições de adentrar nesse ciclo econômico. Uma das consequências indiretas de anos de exploração estrangeira, tais comunidades ficam à margem tanto de políticas econômicas como de qualquer desenvolvimento que delas possa decorrer.

Daí também a importância de uma "política" específica a esses grupos marginais, qual seja, a Economia Solidária. Com investimentos específicos no setor e formas apropriadas de aconselhamento, treinamento e financiamento, a política tem conseguido inserir, por caminhos diferentes, indivíduos, grupos ou comunidades na economia formal brasileira. Fortalecendo-as nas suas condições de excluídas, o movimento da Economia Solidária esmera-se por inseri-las no ciclo econômico somente quando elas têm condição de sobreviver por si sós. Esse processo é bom para os marginalizados, que conseguem integrar o desenvolvimento e tirar dele a sua parte, como para o próprio ciclo econômico, ao qual são adicionadas novas contribuições, novos atores e novos produtos.

Sendo assim, é importante ter em mente o fato de que, na verdade, as moedas sociais são um instrumento de desenvolvimento integrador, e possibilitam a criação de um "produto interno" à comunidade antes que esta possa ser incluída no sistema financeiro e econômico oficial. Há diversas implicações teóricas e empíricas neste processo, mas o presente trabalho tem um objetivo antes descritivo que avaliativo. Em suma, diante da inércia do Estado em promover determinados serviços essenciais, a comunidade tomou as rédeas da situação e implantou um mecanismo não oficial que permite o seu desenvolvimento. Interessante seria se o Estado entendesse por bem restringir agora o que surgiu justamente como resposta à sua inação. Mas isso é tarefa a ser problematizada.

A experiência do Banco Palmas é única na história do Brasil e vem influenciando diversas outras iniciativas. Até que ponto as propostas da Econo- 
mia Solidária efetivamente levam ao desenvolvimento? Esse desenvolvimento afeta, de alguma forma, o desempenho da economia nacional como um todo? E, por fim, será que os idealizadores do movimento tinham por objetivo a sua inclusão no mercado ou justamente a criação de um verdadeiro sistema paralelo e marginal ao sistema financeiro brasileiro? Essas são perguntas que permeiam esta conclusão e às quais não há respostas. Ainda.

\section{Referências bibliográficas}

ASCARELLI, Tulio. Teoria geral dos títulos de crédito. 2. ed. São Paulo: Saraiva, I969.

BOŻYK, Pawel. Globalization and the Transformation of Foreign Economic Policy: Transition and Development. England: Ashgate Publishing Limited, 2006.

GHANG, Ha-Joon. Globalisation, Economic Development and the Role of the State. New York: Zed Books, 2004.

FARIA, José Eduardo. Democracia e governabilidade: os direitos humanos à luz da globalização econômica. In: (Org.). Direito e globalização econômica. São Paulo: Malheiros Editores, 2010.

FURTADO, Celso. Transformação e crise na economia mundial. Rio de Janeiro: Paz e Terra, I987.

HENDERSON, Hazel. Além da globalização. São Paulo: Cultrix, I999.

INSTITUTO PALMAS. 100 perguntas mais frequentes. Fortaleza: Instituto Palmas, 2009.

SINGER, Paul. Desenvolvimento capitalista e desenvolvimento solidário. Estudos Avançados, São Paulo, v. I8, n. 5I, maio/ago. 2004.

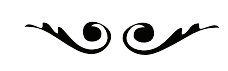

Nicole Fobe - Graduada em Direito pela Faculdade de Direito da Universidade de São Paulo.

nicole.fobe@usp.br 